\title{
MRI of the penis
}

\author{
A KIRKHAM, FRCS, FRCR
}

University College Hospital, London, UK

\begin{abstract}
MRI of the penis is an expensive test that is not always superior to clinical examination or ultrasound. However, it shows many of the important structures, and in particular the combination of tumescence from intracavernosal alprostadil, and highresolution $T_{2}$ sequences show the glans, corpora and the tunica albuginea well. In this paper we summarise the radiological anatomy and discuss the indications for MRI. For penile cancer, it may be useful in cases where the local stage is not apparent clinically. In priapism, it is an emerging technique for assessing corporal viability, and in fracture it can in most cases make the diagnosis and locate the injury. In some cases of penile fibrosis and Peyronie's disease, it may aid surgical planning, and in complex pelvic fracture may replace or augment conventional urethrography. It is an excellent investigation for the malfunctioning penile prosthesis.
\end{abstract}

Received 3 October 2011 Revised 14 March 2012 Accepted 15 March 2012

DOI: $10.1259 / \mathrm{bjr} / 63301362$

(C) 2012 The British Institute of Radiology
The penis is predominantly a superficial organ, and for the most part easily examined by palpation or with ultrasound. Although MRI can be used to assess most penile pathologies, it needs to demonstrate clinical utility to justify its expense. Before discussing the benefits of MRI for a number of pathologies, we will briefly summarise the radiological anatomy and scanning techniques.

\section{Anatomy}

The corpus spongiosum and corpora cavernosa are of high signal on $T_{2}$ weighted sequences, and intermediate to low on $T_{1}$ weighted sequences [1]. The tunica albuginea is a fibrous sheath surrounding all three (Figure 1), and is low in signal on all sequences, with the contrast between it and the higher signal corpora greatest on $T_{2}$ (Figures 2 and 3). The septum divides the two corpora cavernosa and is generally porous, allowing the passage of blood (and agents injected intracavernosally) from one side to the other [2].

Close to the tunica albuginea is Buck's fascia, a slightly less dense fibrous sheath that is only sometimes distinguishable from the deeper tunica [3]. It fuses with the deep perineal fascia, so that haemorrhage from a penile fracture which does not compromise Buck's fascia is confined to the penis, rather than spreading to the perineum. Superficial to Buck's fascia is the thin, incomplete Dartos fascia (not clearly seen on MRI), then loose subepithelial connective tissue and skin. In the glans, the tunica albuginea is hard to distinguish from the more superficial subepithelial connective tissue and the two fuse towards the tip [4].

The deep parts of the corpora cavernosa are closely related to the inferior pubic ramus on each side, and

Address correspondence to: Dr Alex Kirkham, Consultant Radiologist, University College Hospital, 235 Euston Road, London NW1 2BU, UK. E-mail: alex.kirkham@uclh.nhs.uk surrounded by the ischiocavernosus muscle. The most proximal part of the corpus spongiosum is the bulb, which is surrounded by the bulbospongiosus muscle and is pierced by the urethra. The corpus spongiosum is continuous with the glans, and the two generally have the same signal characteristics on MRI.

The vascular anatomy of the penis is very variable [5], but the common penile artery, a branch of the internal pudendal artery, gives three relatively constant branches: crural, dorsal penile (supplying more distal corpus spongiosum and glans) and cavernosal, supplying the corpus cavernosum on each side and often duplicated. Side branches (the helicine arteries) are easily seen on ultrasound but are not usually visible on MRI. The venous anatomy is variable but the largest branches are the superficial and deep dorsal, in the midline, separated by Buck's fascia.

\section{MR sequence}

The mainstay of penile MRI is high-resolution (matrix size $\geq 200$ ), small-field-of-view, thin-slice (ideally $3 \mathrm{~mm}$ ) $T_{2}$ weighted spin echo sequences in 3 orthogonal planes, with the penis in the anatomical position (resting on the anterior abdominal wall in the midline, although others place it dependently to minimise breathing artefact [6]). This is our routine protocol, with further sequences added as required. $T_{1}$ weighted images may be useful for the detection of haemorrhage and thrombosis within the corpora or draining veins. Small field-of-view short-tau inversion-recovery (STIR) sequences may show inflammation, and sometimes the deep veins of the pelvis well. For imaging the cavernosal vessels and corporal enhancement, we use dynamic contrast-enhanced sequences, with 3-4-mm slice thickness and a small field of view, usually in the coronal plane, as it shows the vessels in the base of the penis best. For assessment of 


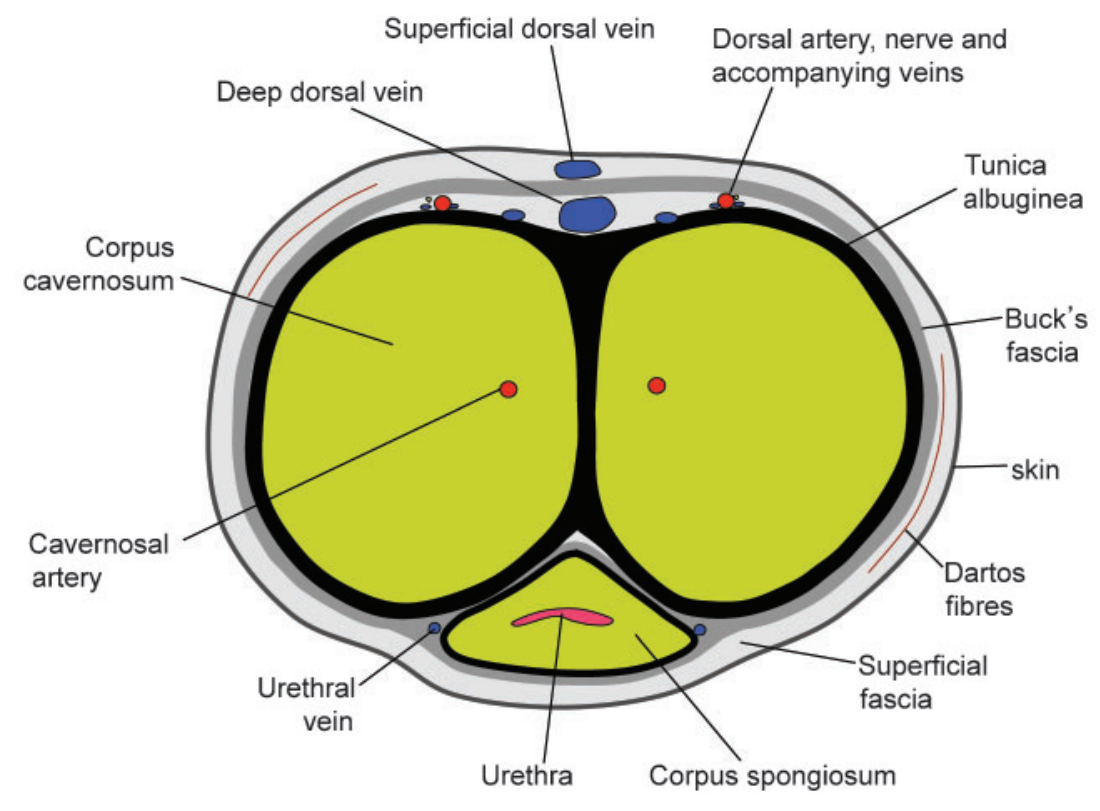

Figure 1. Cross-sectional penile anatomy.

cavernosal viability in priapism, the dynamic scans show early perfusion, but there should be one scan at least $10 \mathrm{~min}$ after contrast-ideally a small field of view spin echo $T_{1}$ weighted sequence, with an identical sequence obtained before contrast for comparison. Contrast enhancement for staging tumours is usually not helpful [7].

\section{Tumescence and intracorporal agents}

There are two reasons for using intracavernosal agents to produce tumescence. First, the normal corpora become uniformly high in $T_{2}$ signal, and the tunica albuginea is seen as a thin, regular low signal layer around them. This makes it much easier to see both intracavernosal fibrosis and tunical plaque, as well as other intracavernosal pathologies such as fistula or tumour. Second, positioning of the tumescent (though ideally not fully so) penis in the midline makes it considerably easier to scan in true sagittal, coronal and axial planes. For young males with normal erectile function we use $5 \mu \mathrm{g}$ of alprostadil, and for older males with erectile dysfunction the full dose of $20 \mu \mathrm{g}$. Priapism is rare, but can be treated in most cases by aspiration [8]. Sildenafil and manual stimulation may produce tumescence in most patients but, especially for
MRI, they are not as reliable as intracavernosal agents [9].

\section{MRI for penile cancer}

The great majority of penile lesions are primary squamous cell tumours, although melanoma, basal cell carcinoma, sarcoma and lymphoma have been reported, and metastases are common enough to account for several cases series, with bladder the commonest site of origin-either haematogenous or from urethral spread of transitional cell carcinoma [10, 11]. Anterior urethral tumours are rare, and usually of the squamous rather than the transitional type [12].

Local staging (the classification is shown in Table 1) of penile cancer may be useful to plan the surgical approach. There is some controversy about the current classification, especially within the glans, which is the site of the majority of tumours [13] (Figure 4). It was noted in an early ultrasound study that the tunica albuginea in the glans becomes difficult to see and blends with subepithelial connective tissue [4]. Not only is the distinction between $\mathrm{T} 1$ and $\mathrm{T} 2$ disease therefore more difficult, but the finding of $\mathrm{T} 2$ disease in the glans has different implications for the same stage in the shaft,

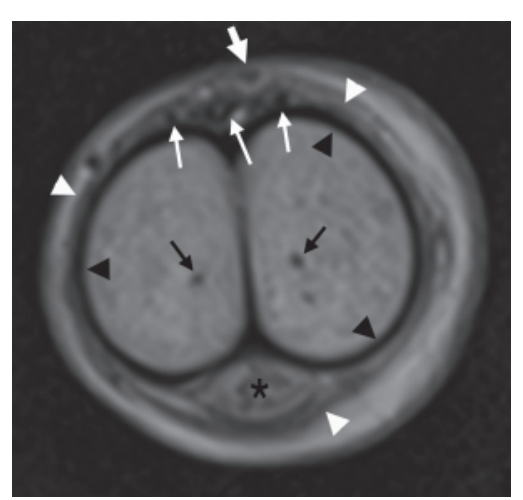

(a)

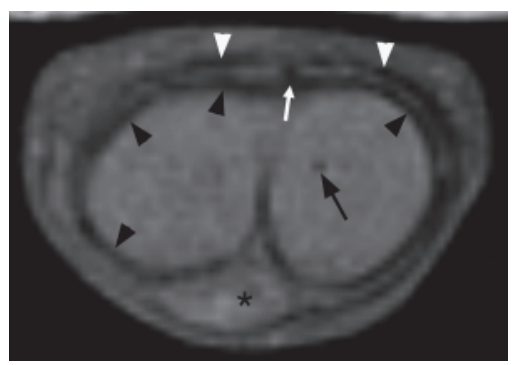

(b)
Figure 2. $T_{2}(\mathrm{a})$ and $T_{1}(\mathrm{~b})$ weighted sequences through the tumescent penis. Black arrowheads mark the tunica albuginea, and white arrowheads Buck's fascia. In (a) the thick white arrow shows the superficial dorsal vein and the thinner white arrows the deep dorsal vessels. The cavernosal arteries are marked by black arrows. The urethra, lying in the middle of the corpus spongiosum, is marked by an asterisk. 


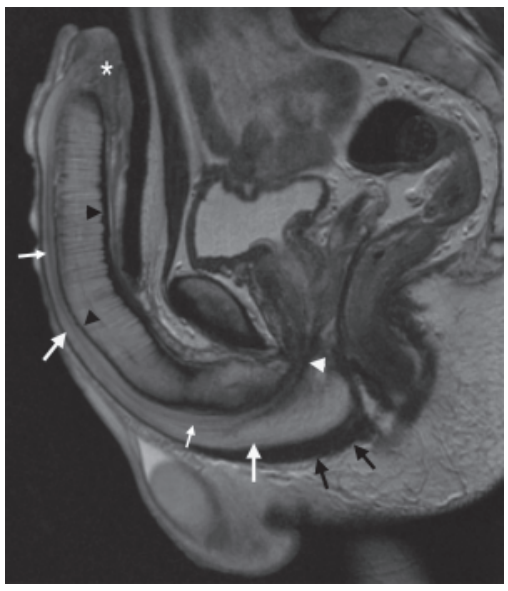

(a)

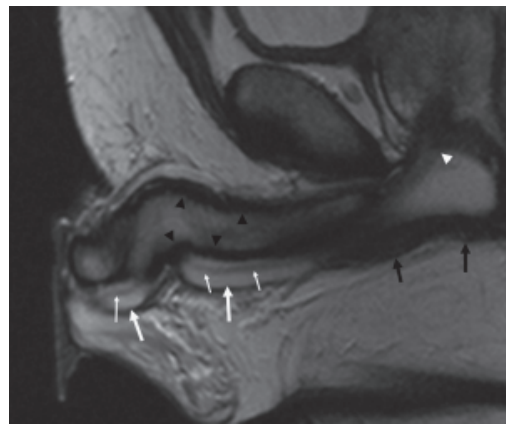

(b)
Figure 3. $T_{2}$ weighted sagittal section close to the midline (a) after intracavernosal alprostadil and (b) without tumescence. Black arrows mark the tunica albuginea, large white arrows the corpus spongiosum, small white arrows the urethra within it, and small black arrows the bulbocavernosus muscle. The white arrow head indicates the entry of the urethra into the roof of the bulb, and an asterisk marks the glans. In (a) the "corrugated" appearance of the corpus cavernosum is because of the midline septum, and normal. Note the considerably thicker tunica albuginea in the detumescent state, and the lower signal in corpus cavernosum; the glans is not in the midline sagittal plane. with glansectomy (partial or complete) the treatment of choice $[14,15]$ as opposed to partial or complete penectomy (and a significantly worse prognosis) in T2 disease involving the corpora cavernosa in the shaft [16]. The T3 classification is also problematic: involvement of the urethra is commonly near the meatus and may have a better prognosis than T2 involvement of the corpus spongiosum in the shaft [17]. These issues have led to the proposal of a new staging system more closely related to prognosis, also shown in Table 1 [18].

Tumour is seen as low signal compared with corpus spongiosum or cavernosum on $T_{2}$ sequences, but usually higher than the tunica (Figure 4). Although MRI provides excellent soft-tissue definition, it does not necessarily follow that it is superior to clinical examination for local staging, and early studies, usually without intracavernosal agents and in small numbers of patients, did not show definitively that it was of benefit. It must be borne in mind that the clinical stage is usually most accurately determined at operation and with the use of frozen section analysis. Later studies, with the use of intracavernosal agents, have shown that MRI was useful when infiltration of the corpora "could not be determined properly by clinical examination" and that MRI is probably better than ultrasound in this context [19]. In particular, several studies have shown that invasion of the corpora cavernosa is rarely missed [7, 19, 20], and proximal tumours, which are hard to scan on ultrasound and difficult to palpate, are shown well. However, even with intracorporal agents MRI can sometimes overstage tumours, and in one study of 55 patients 6 patients with T1 lesions were staged as T2 [20]. This was ascribed to technical factors-poor response to prostaglandin, previous radiotherapy, motion artefact and infection-but it is likely that some of the error was also due to fundamental limits to the resolution of MRI and the difficulty in distinguishing abutment and bulge from true invasion. No cases of priapism were seen, although in a previous smaller study priapism occurred in 1 out of 10 patients [7]. The use of contrast has been anecdotally described as useful [21], but the larger studies do not support its routine use [7]. For superficial lesions clinical examination is usually sufficient.

MRI of the primary tumour can be combined with an examination of the pelvic nodes. Tumour in virtually all cases involves superficial groin nodes first, and from there spreads to deep groin and pelvic nodes [22]. Certain features on MRI are highly specific for involvement-in particular, a fluid component indicating necrosis [6]-but are not common, and in general the most commonly used criterion to determine nodal involvement is short axis diameter. The fundamental limits to MRI are that (1) a small degree of infiltration will not significantly affect the size of a node, and (2) reactive nodal enlargement from local inflammation is particularly common in cancer of the penis, and the cause of nodal enlargement in $25-50 \%$ of palpable groin nodes at presentation [23, 24], although palpable nodes at follow-up are almost always malignant

Table 1. Current and proposed classification for the local staging of penile cancer

\begin{tabular}{lll}
\hline T stage & Current definition & Proposed definition $^{a}$ \\
\hline Tx & Cannot be assessed & Cannot be assessed \\
T0 & No evidence of primary tumour & No evidence of primary tumour \\
Tis & Carcinoma in situ & Carcinoma in situ \\
Ta & Non-invasive verrucous carcinoma & Non-invasive verrucous carcinoma \\
T1 & Tumour invades subepithelial connective tissue & Tumour invades subepithelial connective tissue \\
T2 & Tumour invades corpus spongiosum or corpus & Tumour invades corpus spongiosum \\
T3 & cavernosum & Tumour invades corpus cavernosum \\
T4 & Tumour invades urethra or prostate & Tumour invades adjacent structures (including prostate) \\
\hline
\end{tabular}

${ }^{a}$ According to Leijte et al [18]. 


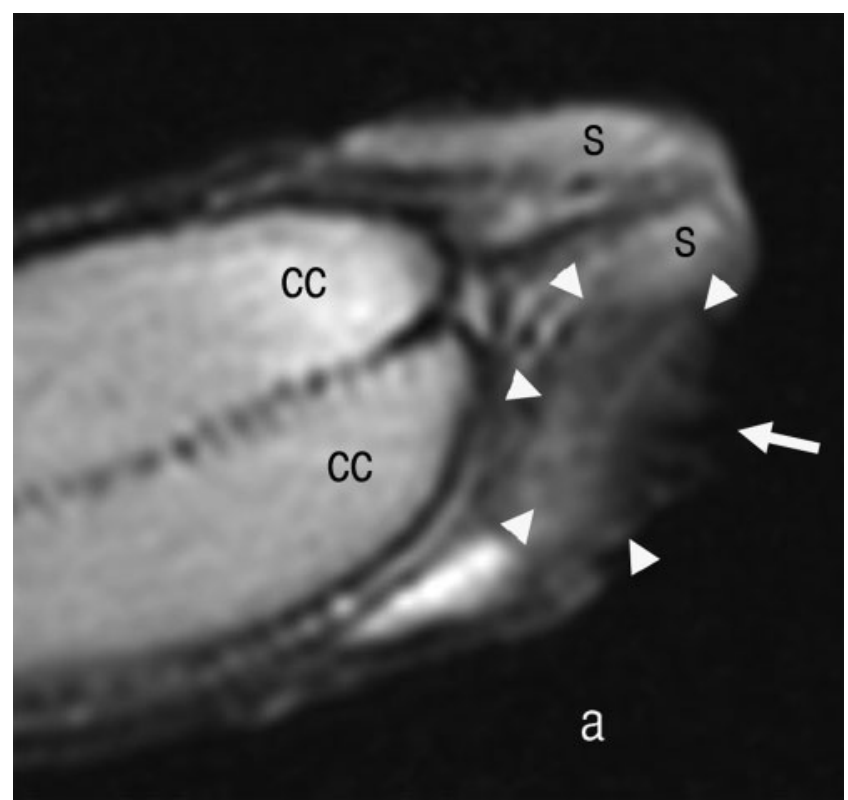

Figure 4. Ulcerating lesion on the glans (white arrowheads, with a white arrow showing the ulcerated part), pT2 on histology and correctly called T2 on MRI. CC, corpus cavernosum; $S$, the spongiosal part of the glans.

[25]. The accuracy of size criteria is little better for pelvic nodes $[26,27]$.

\section{Priapism}

The first important distinction in priapism (prolonged, often painful erection) is the distinction between lowand high-flow states. Low flow is the commonest type and a form of compartment syndrome; as elsewhere in the body if untreated it leads to infarction and fibrosis [28]. It may be caused by several drugs, both therapeutic (including phosphodiesterase inhibitors and intracavernosal agents) and recreational, sickle cell disease, leukaemia and malignant infiltration, although in 30$50 \%$ of cases it is idiopathic [29]. In contrast, in high-flow priapism there is often an arteriolacunar fistula, the corpora are at least initially well oxygenated and there is usually no pain. The distinction between the two states is important, because low-flow priapism requires emergency treatment, but the diagnosis can normally be achieved either clinically, by measurement of blood gases in an aspirate, or on Doppler ultrasound [30].

There are two main indications for MRI. In low-flow priapism (Figure 5) the degree of corporal infarction may influence the decision to intervene, but more definitively if the corpora cavernosa are completely thrombosed after surgical attempts at a shunt, the best functional outcome may be achieved by early insertion of a penile prosthesis [31]. The degree of infarction on MRI correlates well with more established (but less anatomically accurate) methods of assessment such as Doppler and blood gas measurement, and with histology [31]. It is important to emphasise that perfusion of the corpora can be slow, and in addition to dynamically enhanced sequences to assess the patency of the cavernosal arteries, delayed

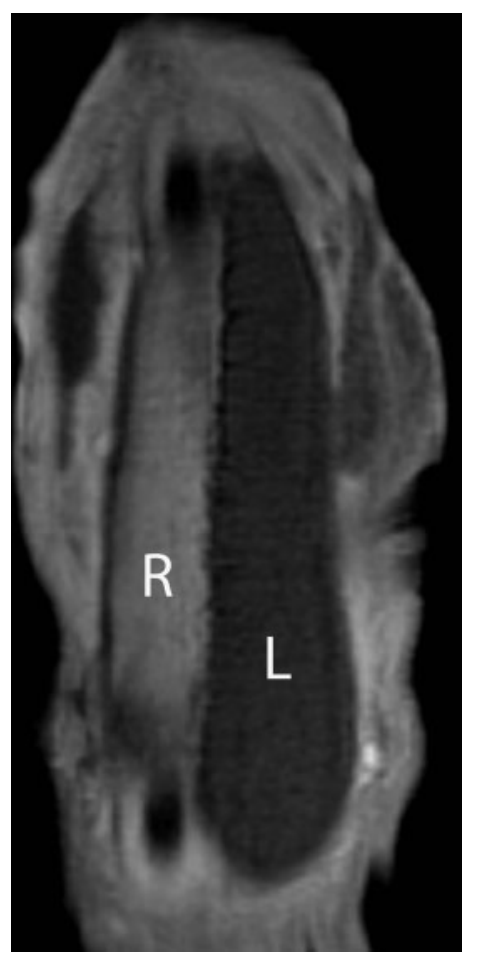

Figure 5. $T_{1}$ weighted scan $10 \mathrm{~min}$ after caverject in lowflow priapism after a right-sided Winter shunt. The left corpus cavernosum (L) is infarcted, and a little expanded, but the right (R) enhances normally. This is an unusual pattern but can be produced by surgical intervention.

sequences at 5 and $10 \mathrm{~min}$ after contrast are necessary to assess tissue viability.

In high-flow priapism, a fistula can be suspected on the dynamic post-contrast images when there is asymmetrical, early enhancement in one corpus, and is often seen as a focus of heterogeneous flow void on $T_{2}$ weighted sequences (Figure 6). However, the combination of ultrasound [30] and angiography is more conventionally used, and is probably more sensitive than MRI, although no direct comparisons have been published.

\section{Penile fracture}

Penile fracture is a traumatic disruption of the tunica albuginea, often felt as a "snap" and usually associated with complete and rapid detumescence. It usually requires urgent surgery to prevent subsequent deformity and erectile dysfunction [32].

The penis should ideally be scanned in the anatomical position (to prevent confusing "kinking") and without intracavernosal agents. The hallmark of a fracture is an interruption of the low-signal tunica albuginea (Figure 7), usually best seen on $T_{2}$ weighted sequences. However, a $T_{1}$ spin echo sequence may show the associated haematoma best, and in one small series was the only sequence that showed the fracture well in three patients; enhancement was not necessary [33].

Identification of the fracture may be useful to the surgeon because a localised exploration may then be performed, rather than an extensive subcoronal degloving procedure [34], which probably has a higher 


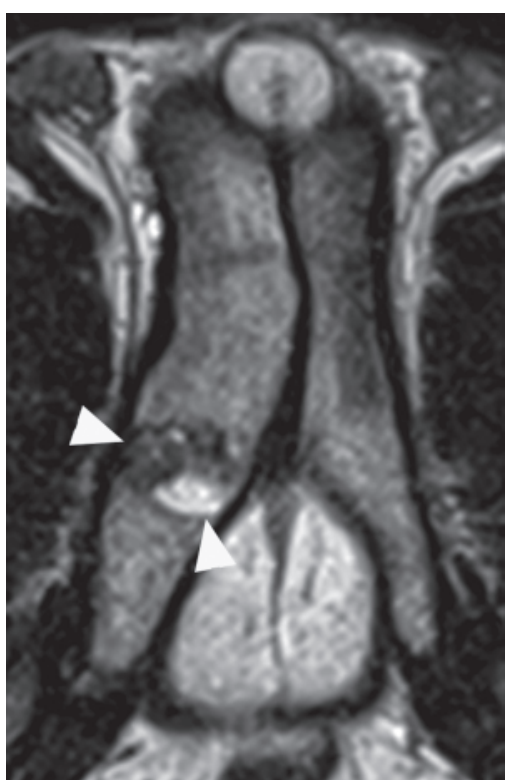

(a)

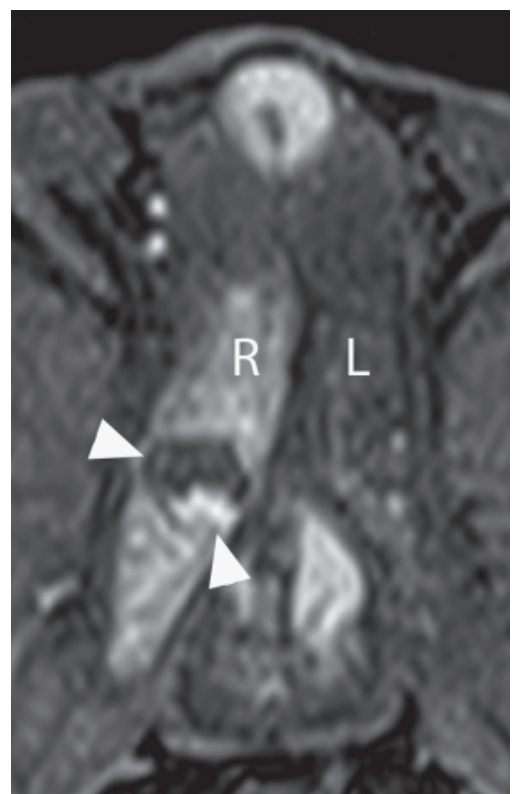

(b)
Figure 6. Axial $T_{2}$ (a) and early dynamic post-contrast gradient echo images (b) in high-flow priapism. The fistula (confirmed on ultrasound and angiography) is shown by the arrowheads in each. It is seen as an area of heterogeneous signal (with elements of flow void) on $T_{2}$, and is associated with earlier enhancement in the right corpus cavernosum (R) than the left (L). post-operative morbidity [35]. MRI detects most fractures (seven out of nine in one series) [36], but should be used with caution when excluding the diagnosis, although there is little doubt that it is more sensitive than ultrasound and cavernosography [37]. Associated urethral injuries may be found in around a quarter of patients, and can be suspected on MRI [33], although urethrography remains the gold standard for their detection. MRI may also detect several pathologies that

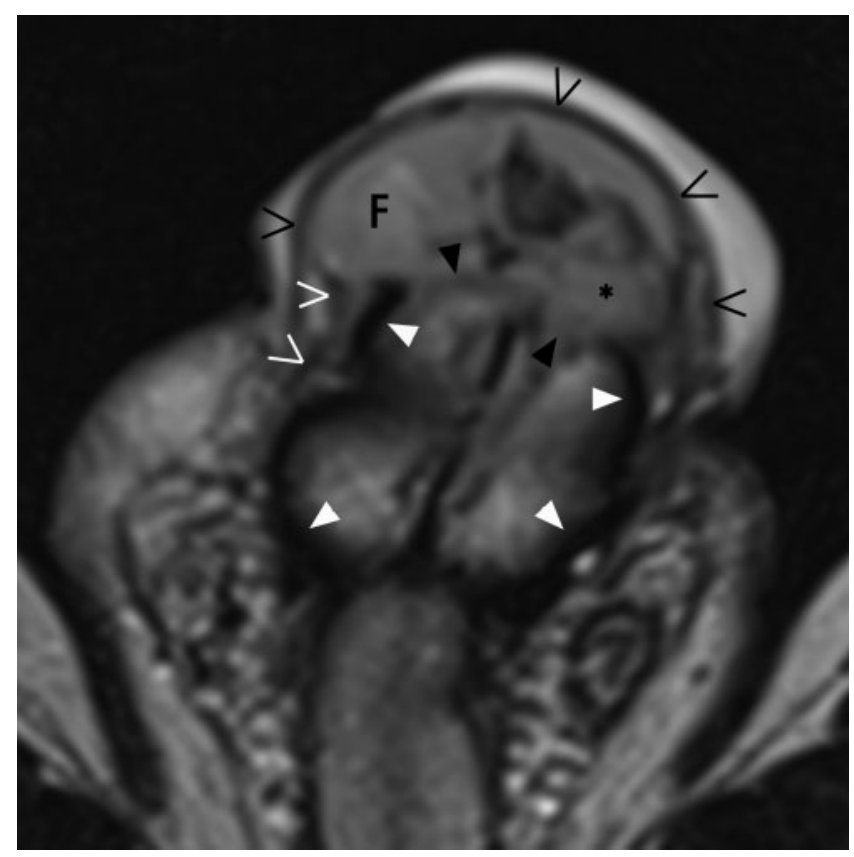

Figure 7. Transverse $T_{2}$ weighted image in a patient with surgically confirmed penile fracture. The white arrowheads show the tunica albuginea, and the white open arrowheads a little of Buck's fascia. A urinoma (F) lies below the Dartos fascia (black open arrowheads). The fracture is seen as a defect in the ventral aspect of both corpora cavernosa (black arrowheads), with, in addition, disruption of the normally high-signal corpus spongiosum (black asterisk). mimic penile fracture-in particular intracavernosal haematoma [34] and rupture of a superficial vein. Although we have been able to diagnose suspensory ligament rupture in one case [3], we do not know the accuracy of MRI in this condition.

\section{Fibrosis and Peyronie's disease}

Fibrosis within the corpora or in the tunica albuginea may result from priapism, trauma or intracavernosal agents [36], but the commonest cause (occurring in around $3 \%$ of males) is Peyronie's disease, defined clinically as a palpable plaque, usually with associated curvature [38], and possibly due to an aberrant healing response to repeated shear strains [39].

Tumescence with intracavernosal agents both improves the sensitivity for plaque and intracavernosal fibrosis (both seen as focal areas of low $T_{2}$ signal) and demonstrates associated angulation or waisting [40] (Figure 8). Although ultrasound may also demonstrate most plaques (and is superior for the detection of calcification) [41], it is probably a little less sensitive (with $67 \%$ and $61 \%$ of palpable plaques demonstrated on MR and ultrasound in one study [41]). Except at the base of the penis, MRI is still probably less sensitive for tunical plaque than clinical examination [41], and is probably not indicated routinely, although it can be useful for surgical planning.

One potential benefit of MRI is the demonstration of tunical enhancement, which in a small series [42] correlated with the initial inflammatory phase of Peyronie's disease, when most surgeons advise against surgery. However, there is little correlation with pain-the most commonly used indicator of active disease [41] —and the significance of plaque enhancement remains uncertain.

Intracavernosal fibrosis (both in Peyronie's disease and post traumatic) may be seen as areas of low-signal stranding, but should not be overdiagnosed: some lowsignal stranding in the distal corpora cavernosa is seen in normal males [3]. 


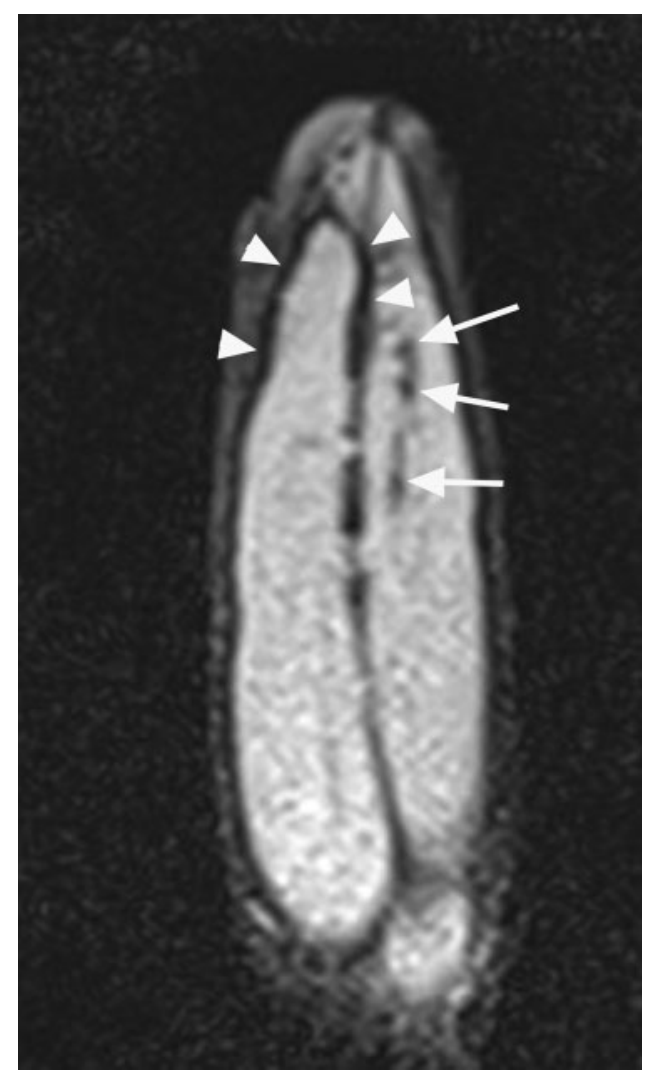

Figure 8. Peyronie's disease. $T_{2}$ coronal image showing tunical plaque in the distal right corpus cavernosum (white arrowheads), with moderate distal waisting. Intracavernosal fibrosis is seen on the left (white arrows).

\section{Implants}

Inflatable implants are all safe in $1.5 \mathrm{~T}$ systems but two malleable prostheses (OmniPhase and DuraPhase; Dacomed, Minneapolis, MN) containing metallic elements show fairly strong deflection in $1.5 \mathrm{~T}$ magnets [43] and should not be scanned.

Inflatable implants are well seen on $T_{2}$ and STIR sequences [44], and we scan with the device inflated when possible. Although ultrasound is sufficient in many cases to check for adequate fluid in the device, several abnormalities are best seen on MRI. In particular, kinking from overlong cavernosal components can be hard to detect clinically, and in one study an anatomical abnormality was seen on MRI in all 14 patients with pain, apparent clinically in only 5 [45]. Crossover of cavernosal components is relatively rare, but well seen [3], as is aneurysmal dilation of the cavernosal components, which may lead to bulge and underinflation (Figure 9). The hypermobile glans, leading to a "supersonic transporter deformity" [46], can be diagnosed clinically or by ultrasound.

Infection occurs in around $2-4 \%$ of inflatable implants (although subclinical infection is more common) [47] and is often associated with periprosthetic fluid and stranding (seen in particular on STIR sequences) [45], but these findings should be interpreted with caution: some fluid does not necessarily imply infection, and stranding may be seen for several months after insertion. We have

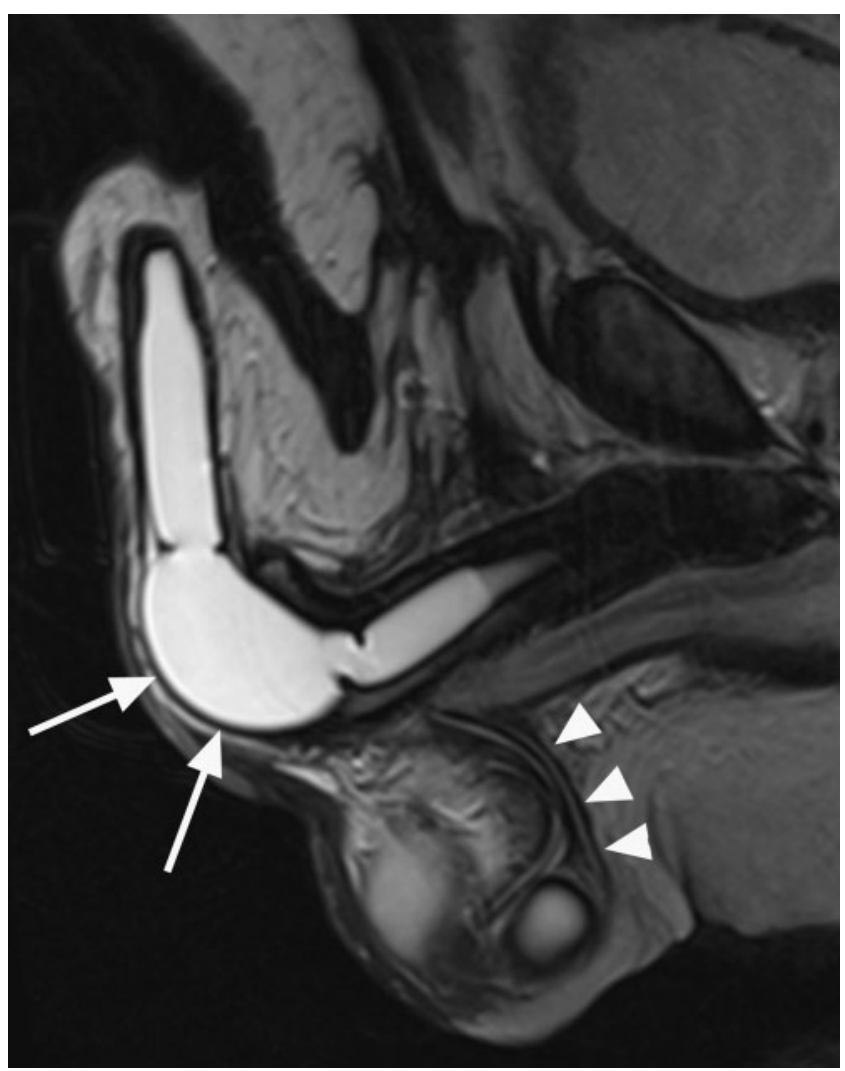

Figure 9. Aneurysmal dilation of the penile prosthesis (white arrow), causing a palpable lump and poor inflation. Note the tubing extending to the pump in the scrotum (white arrowheads). No fluid is seen around it to indicate infection.

found that infections that are convincingly shown on MRI are usually clinically apparent as well.

\section{Erectile dysfunction}

Peyronie's disease and penile fibrosis can both cause erectile dysfunction and can be imaged on MRI. However, clinical tests of nocturnal penile tumescence, response to phosphodiesterase inhibitors and intracavernsoal agents, together with penile Doppler ultrasound remain the mainstay of imaging investigation [48, 49]. MR angiography may demonstrate the branches of the internal iliac vessels, and can be used to plan pelvic revascularisation, but is not of adequate resolution to show the penile vessels well, and conventional angiography is superior [50].

\section{Urethrography}

MR urethrography is technically feasible, but not necessarily straightforward. Compared with conventional urethrography it may sometimes show fistula, tumour, and spongiofibrosis better [51], but similar benefits are seen with ultrasound urethrography of the anterior urethra [52] and both MRI and ultrasound are considerably more cumbersome than a fluoroscopic ascending and descending urethrogram, which is quick, demonstrates 
fistulas well and can show the posterior urethra during voiding.

MR urethrography can be performed with $T_{2}$ sequences and saline or jelly [51] or $T_{1}$ gradient echo sequences around an hour after injection of intravenous gadolinium [53]. One place where MRI may be useful is after pelvic trauma, where as well as delineating the urethral lumen it may demonstrate the anatomical abnormality and degree of prostatic displacement [54]; in particular, one report has suggested that it may be more accurate than conventional urethrography at determining the length of the obliterated segment [55], but it must be stressed that obtaining good urethral distension can be technically challenging. Periurethral enhancement correlates with inflammation but is as yet of uncertain clinical significance [56].

\section{Miscellaneous conditions}

MRI can be used to define the location of injected silicone [57] (in particular using silicone-suppressed sequences) or other substances, and $T_{2}$ and STIR sequences will show dilated Cowper's ducts. Finally, MRI is an excellent tool for defining the anatomy in cases of ambiguous or abnormal genitalia [58].

\section{Conclusion}

MRI can contribute useful information for many different pathologies in the penis, but is in many cases not convincingly superior to clinical examination or ultrasound to justify its routine use. It is probably most useful in the investigation of the painful penile implant and acute low-flow priapism. It is sometimes useful for the local staging of penile cancer, for the localisation of penile fracture and for imaging complex cases of fibrosis.

\section{References}

1. Pretorius ES, Siegelman ES, Ramchandani P, Banner MP. MR imaging of the penis. Radiographics 2001;1:S283-98; discussion S98-9.

2. Velcek D, Evans JA. Cavernosography. Radiology 1982;144: 781-5.

3. Kirkham AP, Illing R, Minhas S, Minhas S, Allen C. MR imaging of nonmalignant penile lesions. Radiographics 2008;28:837-53.

4. Horenblas S, Kroger R, Gallee MP, Newling DW, van Tinteren $\mathrm{H}$. Ultrasound in squamous cell carcinoma of the penis; a useful addition to clinical staging? A comparison of ultrasound with histopathology. Urology 1994;43:702-7.

5. Bookstein JJ, Lang EV. Penile magnification pharmacoarteriography: details of intrapenile arterial anatomy. AJR Am J Roentgenol 1987;148:883-8.

6. Kochhar R, Taylor B, Sangar V. Imaging in primary penile cancer: current status and future directions. Eur Radiol 2009;20:36-47.

7. Scardino E, Villa G, Bonomo G, Matei DV, Verweij F, Rocco $\mathrm{B}$, et al. Magnetic resonance imaging combined with artificial erection for local staging of penile cancer. Urology 2004;63:1158-62.

8. Muruve N, Hosking DH. Intracorporeal phenylephrine in the treatment of priapism. J Urol 1996;155:141-3.
9. Bacar MM, Batislam E, Altinok D, Yilmaz E, Bacar H. Sildenafil citrate for penile hemodynamic determination: an alternative to intracavernosal agents in Doppler ultrasound evaluation of erectile dysfunction. Urology 2001;57:623-6; discussion 6-7.

10. Kendi T, Batislam E, Basar MM, Yilmaz E, Altinok D, Basar $\mathrm{H}$. Magnetic resonance imaging (MRI) in penile metastases of extragenitourinary cancers. Int Urol Nephrol 2006; 38:105-9.

11. Lau TN, Wakeley CJ, Goddard P. Magnetic resonance imaging of penile metastases: a report on five cases. Australas Radiol 1999;43:378-81.

12. Dinney CP, Johnson DE, Swanson DA, Babaian RJ, von Eschenbach AC. Therapy and prognosis for male anterior urethral carcinoma: an update. Urology 1994;43:506-14.

13. Pow-Sang MR, Benavente V, Pow-Sang JE, Morante C, Meza L, Baker M, et al. Cancer of the penis. Cancer Control 2002;9:305-14.

14. Smith Y, Hadway P, Biedrzycki O, Perry MJ, Corbishley C, Watkin NA. Reconstructive surgery for invasive squamous carcinoma of the glans penis. Eur Urol 2007;52:1179-85.

15. Brown CT, Minhas S, Ralph DJ. Conservative surgery for penile cancer: subtotal glans excision without grafting. BJU Int 2005;96:911-2.

16. Minhas S, Kayes O, Hegarty P, Kumar P, Freeman A, Ralph $D$. What surgical resection margins are required to achieve oncological control in men with primary penile cancer? BJU Int 2005;96:1040-3.

17. Leijte JA, Gallee M, Antonini N, Horenblas S. Evaluation of current TNM classification of penile carcinoma. J Urol 2008;180:933-8; discussion 8.

18. Leijte JAP, Horenblas S. Shortcomings of the current TNM classification for penile carcinoma: time for a change? World J Urol 2009;27:151-4.

19. Lont AP, Besnard APE, Gallee MPW, Van Tinteren H, Horenblas S. A comparison of physical examination and imaging in determining the extent of primary penile carcinoma. BJU Int 2003;91:493-5.

20. Kayes O, Minhas S, Allen C, Hare C, Freeman A, Ralph D. The role of magnetic resonance imaging in the local staging of penile cancer. Eur Urol 2007;51:1313-8; discussion 8-9.

21. de Kerviler E, Ollier P, Desgrandchamps F, Zagdanski AM, Attal $\mathrm{P}$, Teillac $\mathrm{P}$, et al. Magnetic resonance imaging in patients with penile carcinoma. Br J Radiol 1995;68:704-11.

22. Protzel C, Alcaraz A, Horenblas S, Pizzocaro G, Zlotta A, Hakenberg OW. Lymphadenectomy in the surgical management of penile cancer. Eur Urol 2009;55:1075-88.

23. Pizzocaro G, Algaba F, Horenblas S, Solsona E, Tana S, Van Der Poel $\mathrm{H}$, et al. EAU Guidelines on penile cancer. EAU; 2009 [accessed April 2012]. Available from: http://www. uroweb.org/nc/professional-resources/guidelines/online/

24. Hughes B, Leijte J, Shabbir M, Watkin N, Horenblas S. Noninvasive and minimally invasive staging of regional lymph nodes in penile cancer. World J Urol 2009;27:197-203.

25. Ornellas AA, Seixas AL, Marota A, Wisnescky A, Campos F, de Moraes JR. Surgical treatment of invasive squamous cell carcinoma of the penis: retrospective analysis of 350 cases. J Urol 1994;151:1244-9.

26. Eisner BH, Feldman AS. Nanoparticle imaging for genitourinary cancers. Cancer Biomark 2009;5:75-9.

27. Hovels AM, Heesakkers RA, Adang EM, Jager GJ, Strum S, Hoogeveen $\mathrm{YL}$, et al. The diagnostic accuracy of $\mathrm{CT}$ and MRI in the staging of pelvic lymph nodes in patients with prostate cancer: a meta-analysis. Clin Radiol 2008;63:387-95.

28. Pryor J, Akkus E, Alter G, Jordan G, Lebret T, Levine L, et al. Priapism. J Sex Med 2004;1:116-20.

29. El-Bahnasawy MS, Dawood A, Farouk A. Low-flow priapism: risk factors for erectile dysfunction. BJU Int 2002;89:285-90. 
30. Wilkins CJ, Sriprasad S, Sidhu PS. Colour Doppler ultrasound of the penis. Clin Radiol 2003;58:514-23.

31. Ralph DJ, Borley NC, Allen C, Kirkham A, Freeman A, Minhas $S$, et al. The use of high-resolution magnetic resonance imaging in the management of patients presenting with priapism. BJU International 2010;106:1714-8.

32. Kalash SS, Young JD, Jr. Fracture of penis: controversy of surgical versus conservative treatment. Urology 1984;24: 21-4.

33. Uder M, Gohl D, Takahashi M, Derouet H, Defreyne L, Kramann B, et al. MRI of penile fracture: diagnosis and therapeutic follow-up. Eur Radiol 2002;12:113-20.

34. Abolyosr A, Moneim AE, Abdelatif AM, Abdalla MA, Imam HM. The management of penile fracture based on clinical and magnetic resonance imaging findings. BJU Int 2005;96:373-7.

35. Morris SB, Miller MA, Anson K. Management of penile fracture. J R Soc Med 1998;91:427-8.

36. Choi MH, Kim B, Ryu JA, Lee SW, Lee KS. MR imaging of acute penile fracture. Radiographics 2000;20:1397-405.

37. Fedel M, Venz S, Andreessen R, Sudhoff F, Loening SA. The value of magnetic resonance imaging in the diagnosis of suspected penile fracture with atypical clinical findings. J Urol 1996;155:1924-7.

38. Schwarzer U, Sommer F, Klotz T, Braun M, Reifenrath B, Engelmann U. The prevalence of Peyronie's disease: results of a large survey. BJU Int 2001;88:727-30.

39. Jalkut M, Gonzalez-Cadavid N, Rajfer J. Peyronie's disease: a review. Rev Urol 2003;5:142-8.

40. Levine LA, Lenting EL. A surgical algorithm for the treatment of Peyronie's disease. J Urol 1997;158:2149-52.

41. Hauck EW, Hackstein N, Vosshenrich R, Diemer T, Schmelz $\mathrm{HU}$, Bschleipfer $\mathrm{T}$, et al. Diagnostic value of magnetic resonance imaging in Peyronie's disease-a comparison both with palpation and ultrasound in the evaluation of plaque formation. Eur Urol 2003;43:293-9; discussion 9-300.

42. Helweg G, Judmaier W, Buchberger W, Wicke K, Oberhauser H, Knapp R, et al. Peyronie's disease: MR findings in 28 patients. AJR Am J Roentgenol 1992;158: 1261-4.

43. Shellock FG, Morisoli S, Kanal E. MR procedures and biomedical implants, materials and devices: 1993 update. Radiology 1993;189:587-99.

44. Thiel DD, Broderick GA, Bridges M. Utility of magnetic resonance imaging in evaluating inflatable penile prosthesis malfunction and complaints. Int J Impot Res 2003;15(Suppl. 5):S155-61.

45. Moncada I, Hernandez C, Jara J, Hernandez L, Lafuente J, Lledo E, et al. Buckling of cylinders may cause prolonged penile pain after prosthesis implantation: a case control study using magnetic resonance imaging of the penis. J Urol 1998;160:67-71.

46. Mulhall JP, Kim FJ. Reconstructing penile supersonic transporter (SST) deformity using glanulopexy (glans fixation). Urology 2001;57:1160-2.

47. Carson CC. Diagnosis, treatment and prevention of penile prosthesis infection. Int J Impot Res 2003;15(Suppl. 5): S139-46.

48. Golijanin D, Singer E, Davis R, Bhatt S, Seftel A, Dogra V. Doppler evaluation of erectile dysfunction-part 1 . Int J Impot Res 2007;19:37-42.

49. Golijanin D, Singer E, Davis R, Bhatt S, Seftel A, Dogra V. Doppler evaluation of erectile dysfunction-part 2. Int J Impot Res 2007;19:43-8.

50. John H, Kacl GM, Lehmann K, Debatin JF, Hauri D. Clinical value of pelvic and penile magnetic resonance angiography in preoperative evaluation of penile revascularization. Int J Impot Res 1999;11:83-6.

51. Osman Y, El-Ghar MA, Mansour O, Refaie H, El-Diasty T. Magnetic resonance urethrography in comparison to retrograde urethrography in diagnosis of male urethral strictures: is it clinically relevant? Eur Urol 2006;50:587-93; discussion 94.

52. Gupta N, Dubey D, Mandhani A, Srivastava A, Kapoor R, Kumar A. Urethral stricture assessment: a prospective study evaluating urethral ultrasonography and conventional radiological studies. BJU Int 2006;98:149-53.

53. Yekeler E, Suleyman E, Tunaci A, Tunaci M, Balci NC, Onem K, et al. Contrast-enhanced 3D MR voiding urethrography: preliminary results. Magn Reson Imaging 2004;22: 1193-9.

54. Sung DJ, Kim YH, Cho SB, Oh YW, Lee NJ, Kim JH, et al. Obliterative urethral stricture: MR urethrography versus conventional retrograde urethrography with voiding cystourethrography. Radiology 2006;240:842-8.

55. Oh MM, Jin MH, Sung DJ, Yoon DK, Kim JJ, Moon DG. Magnetic resonance urethrography to assess obliterative posterior urethral stricture: comparison to conventional retrograde urethrography with voiding cystourethrography. J Urol 2010;183:603-7.

56. Pavlica P, Barozzi L, Menchi I. Imaging of male urethra. Eur Radiol 2003;13:1583-96.

57. Oen A, Bergers E, Kanhai R, Hage J, Manoliu R. Magnetic resonance imaging of injected silicone: findings in seven male-to-female transsexuals. Eur Radiol 2002;12:1221-7.

58. Secaf E, Hricak H, Gooding CA, Ho VW, Gorczyca DP, Ringertz $\mathrm{H}$, et al. Role of MRI in the evaluation of ambiguous genitalia. Pediatr Radiol 1994;24:231-5. 